\title{
IMPROVING THE LEARNING PROCESS IN THE SUBJECT OF BASIC MARITIME TRAINING USING GPS AND GOOGLE EARTH AS USEFUL TOOLS
}

\author{
Bismarck Jigena ${ }^{1}$, Amos de Gil ${ }^{1}$, Jorge Walliser ${ }^{1}$, Juan Vidal ${ }^{1}$, Juan José \\ Muñoz ${ }^{1}$, Laura Pozo ${ }^{2}$, Julián Lebrato ${ }^{2}$ \\ ${ }^{1}$ University of Cadiz (SPAIN) \\ ${ }^{2}$ University of Seville (SPAIN)
}

\begin{abstract}
The University College of Marine, Nautical and Radioelectronics Engineering (EINAMAR) of the University of Cadiz is in the process of transition to the new educational system according to the European Higher Education Area (EHEA). New technologies can be introduced in some professional subjects that are fundamental in the training of the future Merchant Marine Officer. The application of these technologies to real cases offers the possibility of improving student learning. Basic Maritime Training is a fundamental subject in the three nautical sciences degrees, and once approved it allows the professional title of Seaman to be used, issued by the Merchant Marine Directorate. Firstly, we will introduce an experimental practice having four academic hours which will provide an understanding of the fundamental concepts of navigation and pilotage. To do this, we used low cost GPS navigation receivers and the free tool of Google Earth. This practice is mandatory and will be assessed together with navigation practicals aboard the sail training vessel "Tartessos", and other practical work of the subject, with a percentage of $20 \%$ of the final exam. The practice improves knowledge in the topics of navigation in the subject. Upon completing this course and fulfilling the objectives of the practice, the student will be more proficient, with the following providing an improvement in the learning process:
\end{abstract}

a) Introduction to the new technologies and their applications in real and professional cases, which is fully compatible with the theoretical content of the subject.

b) Learning and / or updating basic concepts of navigation and pilotage that have been taught during the lectures and applied objectively with the help and use of new technologies.

c) Introduction to e-learning educational technology in this subject.

d) The learning progress of the students will be checked during the practice.

e) New training material and the use of new media will be facilitated in order to improve the learning and understanding of this subject.

At the end of the course, we will assess the success of this initiative by means of survey analyses among the students, as well as the comparison of grading scales obtained in other years with those of the reference year.

Keywords: maritime training, new technologies, navigation practice, GPS, Google Earth, learning, elearning.

\section{INTRODUCTION}

Spanish universities are in a period of change to adapt the structure of university courses to the requirements of the new European Higher Education Area (EHEA). The main objective of the EHEA is to improve the international competitiveness of the universities of the European Union. The university community must jointly establish good practices and values that guarantee the quality of higher education. The adaptation of the university degrees to the new framework of the EHEA, demands that all Andalusian universities improve their quality by means of the substitution of excessively theoretical education by an active education, based on a more practical training and on the use of new technologies [1], with the participation of the students in the learning process also being of special interest [2]. Engineering or technical degrees have always been characterised by a large number of failures [3].

To carry this process forward, Spanish universities must try to apply communication and information technologies (ICTs) in university teaching, with the purpose of improving the education / learning 
process. Therefore, the role of the CITs is to animate the students to seek their own resources and to try new working methodologies through the CITs, as Rubia and Marbán [4] indicate. Some experimental procedures have already been implemented within other engineering subjects (such as the Coastal Engineering course in the Marine and Environmental Sciences Faculty) to decrease academic failure and to allow students to achieve better grades [5]. As a result, the process of European convergence in the curricula has led to the implementation of teaching methodologies that are focused on the independent work of the students [6], which, together with feedback, will result in positive learning benefits in comparison with other teaching aspects, as Black and Wiliam [7] indicate. In this context, we want to implement the use of CITs, new technologies and practical cases in maritime studies [8] [9] [10] in the Subject of Basic Maritime Training. For this, we use the Global Navigation Satellite Systems (GNSS) and the Google Earth computer application which, combined, provide a very powerful tool in the training of the students and future pilots of the Merchant Marine.

From 1960, the GNSS have experienced an unstoppable advance and are now used massively[11]. The American Global Positioning System (GPS) is the most extensive currently used GNSS, providing real time positioning with sufficient precision for navigation. It is established by a global reference framework defined by a network of high precision stations for monitoring GPS satellites, anywhere on the planet and independently of time, climatologic or meteorological conditions [12] [13]. The increasingly lower cost of basic navigation receivers has added to this advance [13]. As [12] and 8[] indicate, the applications of Positioning with GPS are almost limitless, being subject solely to the human imagination. Among these application can be highlighted, by their use and importance, maritime, terrestrial and aerial navigation, geodesy and geodynamics, cartography, topography, hydrography, oceanography and as support to almost all the branches of engineering and the monitoring of physical phenomena and events and of vehicles.

The GPS receiver is excellent for three basic positioning tasks: i) knowing the destination position, which makes arriving there much easier, ii) giving our precise position at any moment, and, iii) having the capacity to store the positions or routes, aiding the return by those same points. Thus, using the points or the indicated routes and marking them on a paper or digital map, whether at sea, on land or in the air, the GPS receiver is an indispensable tool for planning or undertaking navigation [13].

Google Earth (GE) is a computer application with free basic services on the Internet, which include digital cartography at the global level with an accuracy level of less than 10 metres, which is acceptable for navigation applications. The cartographic program of GE visualises cartography at global level, generated by superimposition of satellite images, aerial photographs, maps and geographic information from Geographic Information System (GIS) data models throughout the world, the rights to which have been ceded for their publication on the web. The first version of the program was put on the web in 2005. This program is available through several types of payment licences and a free version, which, although it has limited services, covers navigation needs. This version is the most popular and is available for different types of mobile electronic devices, tablets and personal computers and for different operating systems (Windows, Mac, Linux, and Android). The free version also allows the user to add their own data, and also has the capacity to show different geographic information layers superimposed on the satellite image or the cartography, being a valid client for Web Map Services (WMS), and also supports three-dimensional geospatial data by means of *.kml (Keyhole Markup Language) files[14] [15].

The combined use of GPS navigation receivers whose data can be integrated into GE allows their use in navigation, thereby allowing GE and GPS to be used as a basic electronic chart and gyrocompass, to plan and program the course of a vessel with excellent precision in real time. GE and GPS combined can also be used in mobile devices and tablets in operating systems for iPhone and Android, having the basic application of finding the user's location with GE, which, when integrated with the cartographic application, allows the locations to be seen on the satellite image or the map in $2 \mathrm{D}$ and $3 \mathrm{D}$. For the application to work optimally, a good Internet connection is necessary, either a WiFi network, $3 \mathrm{G}$ or $4 \mathrm{G}$ mobile connections or other type of high speed data connection.

\subsection{Students and the subject of Basic Maritime Training (BMT)}

The subject of BMT is included in the first course in the new degrees of Marine Engineering, Nautical Engineering and Maritime Transport and Radioelectronic Engineering that are taught to the students of the University College of Marine, Nautical and Radioelectronic Engineering (EINAMAR) at Puerto Real (Cadiz). It is a core subject that is taught in the three specialist nautical degrees. The subject provides the students with a global approach and the basic knowledge of the sciences and techniques of sailing navigation, to enable decision making in difficult situations which may represent a risk to the 
life of a crew member or to the safety of the vessel. The subject is organised into different teaching modules which include safety at sea, theory of the vessel and marine technology, vessel manoeuvring, marine meteorology, coastal navigation, mechanical propulsion, radio communications, collision regulations and maritime signalling, bad-weather sailing, emergencies aboard and marine ecology. The subject is completed with seminars and practicals aboard the sailing vessel "Tartessos". In addition to that indicated previously, a very important point of this subject is that it must be passed, together with the subject of Maritime Safety, in order to obtain the Professional Title of Deck Rating (or Engine Rating depending on the specialty) of the Merchant Marine. This qualification allows signing on to the crew aboard vessels of the Spanish Merchant Marine, and also qualifies for the title of Pleasure Craft Skipper, which authorises sailing up to 12 miles from the coast, in command of pleasure craft under motor or sail of up to 15 metres of length [16].

Nevertheless, and in spite of the broad content of the subject, there is a lack of a practical component whereby the student can acquire greater abilities in navigation and skills aboard the vessel. In order to improve this deficiency, we wish to involve the student in the solution of real problems with the aid of the new technologies. For this purpose we propose a series of practical exercises making use of GPS receivers and the GE application, with which the student will plan the navigation course and sail it using the set course with the aid of GPS receivers and marking their position in GE. The accomplishment of these exercises is directly related to the solution of real problems, and requires the active participation of the students in the classroom, in the planning of the exercises, in the practical exercises of the seminars, as well as during the practicals aboard the Tartessos training vessel.

With the start of these practicals and this innovating methodology, we hope that the students will have an experience and an adaptation to the professional environment in a real and effective practical manner, introducing the use of the new technologies applied to their working environment. This will help to clarify and to fix the basic concepts that will later be able to be applied with greater confidence in professional practice and the responsibilities as Seaman or Pleasure Craft Skipper. This methodology will also help to organise the work of the teacher in the context of the teaching / learning process, and for the students the process will be made naturally and spontaneously and will animate them to seek and to relate ideas, general principles and functional knowledge, as indicated by [17]. The main contribution of this work is the improvement of the teaching / learning process on the basis of real experiences and exercises that will give rise to the development of excellent channels of feedback which will obtain better academic results, as indicated by [18].

\section{EQUIPMENT AND METHODOLOGY}

For the implementation of this new methodology and the accomplishment of the proposed exercises, specific equipment and software are needed: computers with connection to the Internet, portable GPS receivers for navigation and with connection to a PC. The software used will be Google Earth, GPS Visualizer and the MapSource programs. All the software used is freeware. The practical consists of the following exercises:

\subsection{Preliminary exercise}

This will be made to familiarise the students with the use of GPS receivers and the software used [19]. The first part of the exercise will be carried out in the computer room, and the second part of the exercise will be carried out in the field. The students will be organised in teams of two. Each team will have a GPS receiver and a computer. Each team will have to undertake the following activities in the practical: 


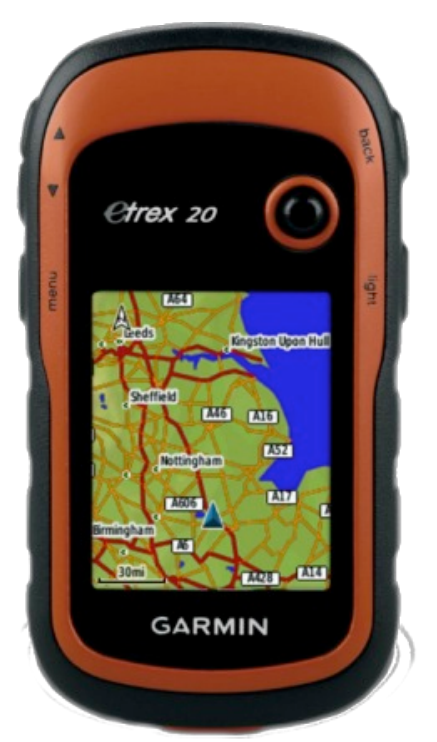

Figure 1. Garmin navigation receiver, model Etrex 20

\subsubsection{Basic use of the GPS receiver to make navigation activities.}

The students will be introduced to the use of a GPS navigation receiver. We will use Garmin receivers, model Etrex 20 or better, with connection to a PC via USB and capacity to load maps [19]. With this equipment the following topics will be covered:

- Start-up and explanation of the parts of the equipment

- Reference systems used by the receiver

- Satellite acquisition

- Calibration of the compass and use of positions

- Setting a waypoint

- Creating a route

- Tracking a route

- Navigating to a destination

\subsubsection{Use of Google Earth (GE) combined with the GPS receiver.}

As a second part of the preliminary exercise, the cartographic mode of GE will be used, whether by using maps or satellite images [14]. Using this software the following topics will be covered.

- Explanation on its environment

- Cartographic systems used

- Coordinates system used

- Map orientation 


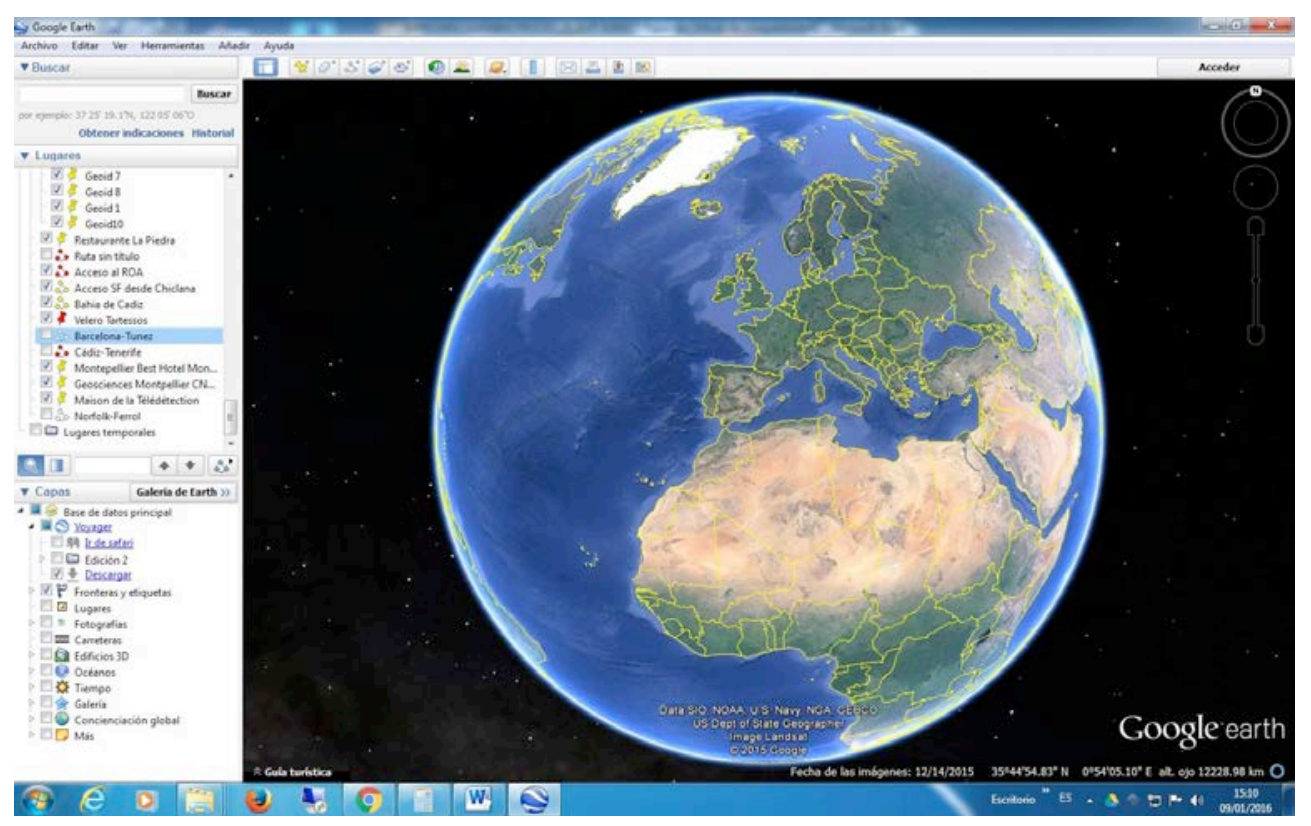

Figure 2. Google Earth software start-up screen

\subsubsection{Location in GE of the geographical coordinates of a known point}

In order to locate a place or a point and to obtain its coordinates in GE, the "Search" window is used, the address of the building in which we are located is entered, e.g. "Puerto Real Campus".

The zoom function and the cursor can be manipulated, observing the geographical coordinates of the cursor in the status bar in the lower part of the image. If the status bar is not visible, select "Status bar" in the "View" menu. The exercise will be carried out in the field, e.g., in the carpark of our College.

\subsubsection{To create waypoints (WP) and routes in Google Earth}

In order to create new WPs, select "Add", then "Placemark". A "Google Earth-New Placemark" window opens, and the "placemark" icon appears centred in the window. The icon can be moved with the mouse to the exact place where we want to create the WP, observing that the coordinates of the point vary as the icon is moved. Once the WP is positioned, it can be given a name and a description.

In order to modify a WP, choose "Places" in the left hand menu and click on the WP or its name with the right mouse button, then choose "Properties" by clicking with the left mouse button. The geographic position and the characteristics of the label and icon can be changed.

In order to create a route in GE, select "Add" then "Path", which opens the "Google Earth - New Path" window. The desired route is created with the main mouse button. Once finished, the created route can be given a name and description.

In order to modify the route, click on the route or on the name of the route with the right mouse button than choose "Properties" with the left mouse button, and the desired parameter changes can be made.

\subsubsection{To keep the information created in a *. $\mathrm{kml}$ file}

A KML file contains geographic data. By means of KML files, different places can be located in a map that are related. KML files have been developed to be managed with the Google Earth program, and can also be used with the Google Maps application. We can now convert the created WPs and routes into KML files: 
The elements created have been added to the side bar of Google Earth under their chosen names. Place the cursor on the element to be saved, which can be done in the side bar or the main screen. Press the right mouse button and then select "Save Place As" from the drop down menu with the left mouse button. In the emergent window, choose the directory where it is required to store the element and in "Save as type" choose $\mathrm{KML}\left({ }^{*} . \mathrm{kml}\right)$. A file has now been created in the corresponding location that has the element that we wanted to store and with the name of the label. In Figure 3 we can see the points and the routes marked with the menu for their storage as KML files.

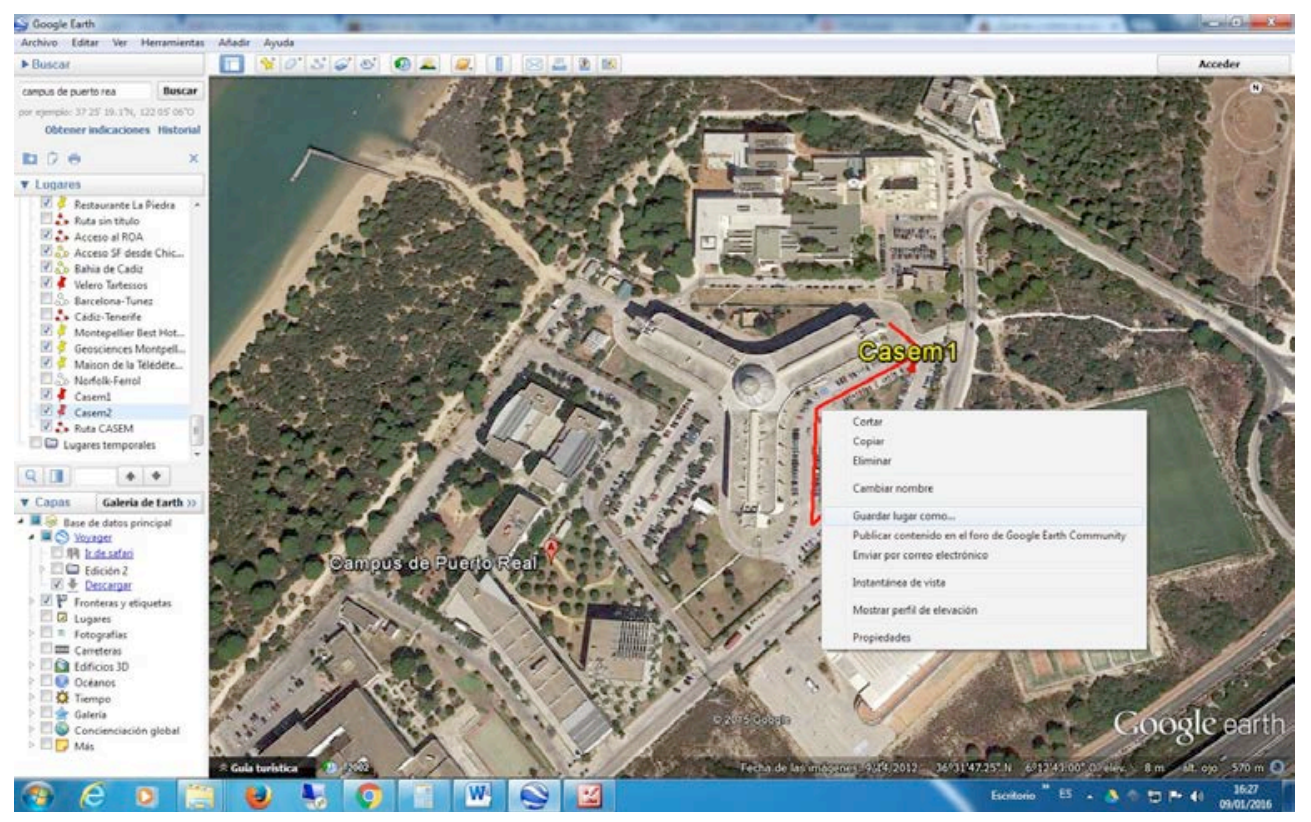

Figure 3. Storing waypoints and routes in $\mathrm{KML}$ files in GE

This program has more functions that can be used, such as the layout of routes, calculation of distances, 3D views, etc. In order to gain more knowledge on these topics, we recommend accessing the help contents of the program. For more information on the KML files or Google Earth, the following addresses can be consulted:

Main page of Google Earth: https://www.google.com/earth/

To download Google Earth: https://www.google.es/intl/es/earth/download/ge/agree.html

Google Maps: https://www.google.es/maps

\subsubsection{Transformation of *. $\mathrm{kml}$ files into *.gpx files:}

The GPS receivers that we are going to use, in this case Garmin, do not understand this *.KML file format so we must translate it to a valid format for this type of receiver, in this case the *.gpx format. The GPX format (GPS Exchange Format) is a light XML format for the exchange of GPS data (waypoints, routes and tracks) between applications and Web Services.

For this step we will use the free, on-line Web application service GPSVisualizer. The program can be executed at the Web address http://www.gpsvisualizer.com. 


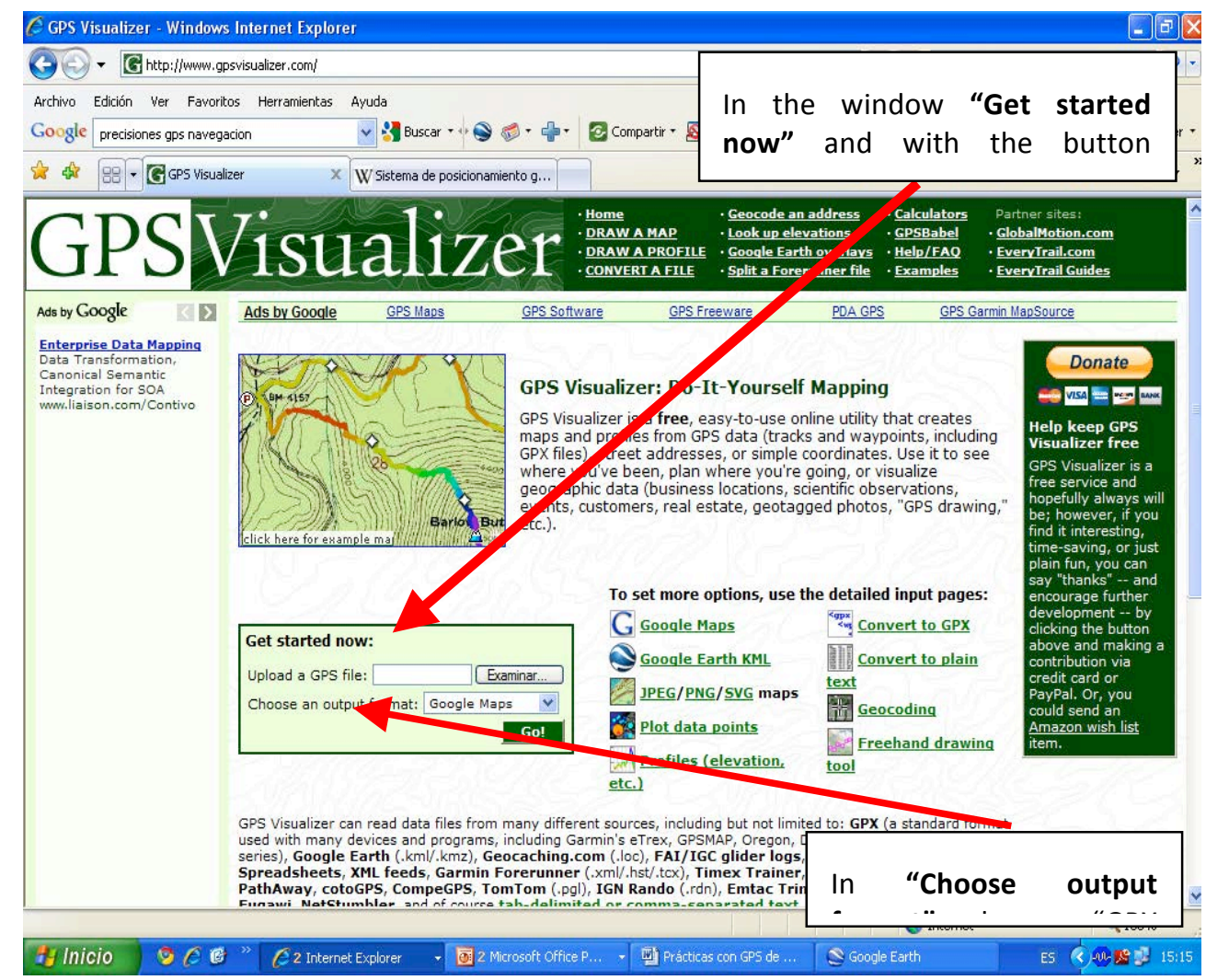

Figure 4. GPSVisualizer and its options to transform KML files

With the button "Convert it" a GPX file is generated that can be downloaded by pressing the link that appears in the following window "Click to download filename-data.gpx". The process is made file to file, and the process is repeated to transform the files that we need (waypoints/routes).

\subsubsection{Loading and verification of waypoints and routes loaded in the GPS receivers}

To load waypoints (WPs) and routes in *.gpx format onto the GPS receiver, the MapSource software from Garmin is used. This software helps to plan your routes and allows the transfer of maps, WPs, routes and tracks from the computer to the Garmin device. The upload to the device is made in the following manner:

- Open the Mapsourcce program

- In the Open File menu choose the *.gpx file that we want to load

- The element appears on the screen

- Ensure that the GPS device is connected to the computer

- Press the icon "send to device"

In order to verify the work carried out in the computer room, we go into the street to the area which has had waypoints and routes memorised. We can go to one of the memorised waypoints or follow the track, the trackback option of the device, and follow the planned route.

\subsubsection{To create and save waypoints, routes and tracks in the GPS receiver. Downloading data from the GPS receiver to GE}

The WPs are locations that are recorded and saved in the GPS device, e.g., we can save the present location as a WP. A route is a sequence of WPs that takes you to a final destination. A track is a recording of the route. The track log contains information on the points of the recorded route, including the time, the position and the height of each point.

In order to create and to save a WP, route or track in the GPS receiver, select the desired option and save in the internal memory of the receiver. 
To download the WPs, routes or tracks taken in the field, from the receiver to GE, select "Tools" in the GPS device menu. Select the type of GPS and import. The imported elements will appear on the GE screen.

\subsection{Final Exercise}

In the second exercise, the students will have to plan the course to navigate aboard the "Tartessos" Training Vessel of the University of Cadiz, shown in Figure 5.

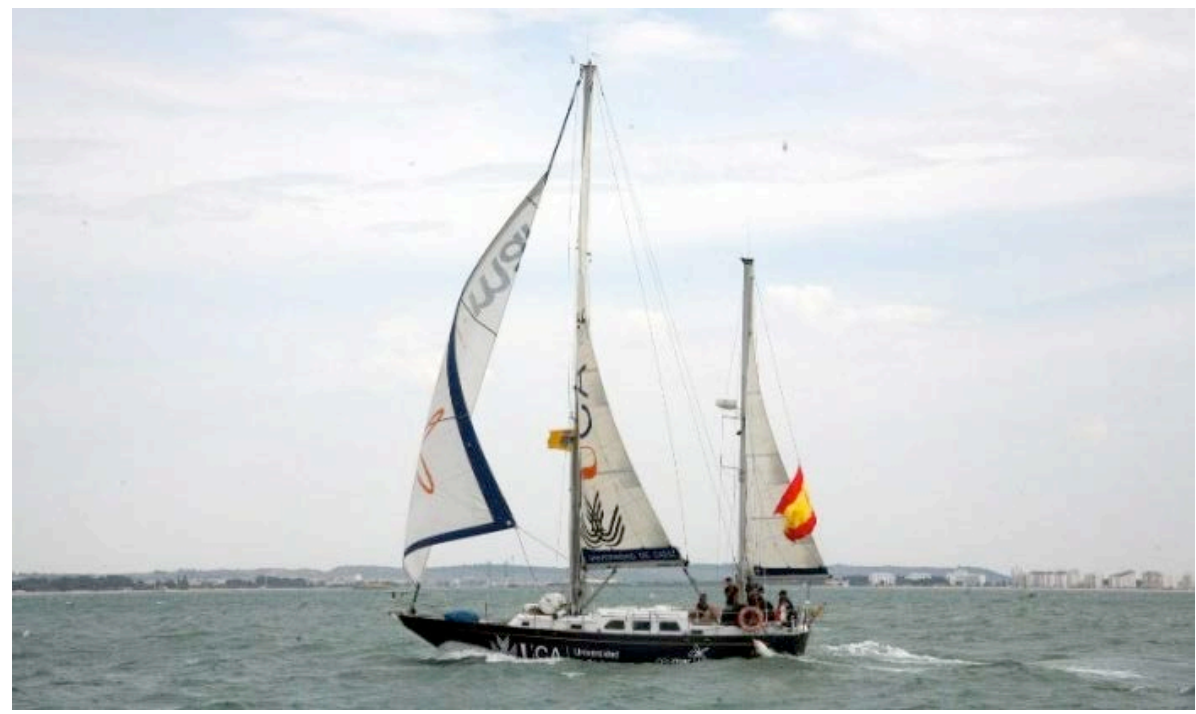

Figure 5. "Tartessos" Training Vessel of the University of Cadiz

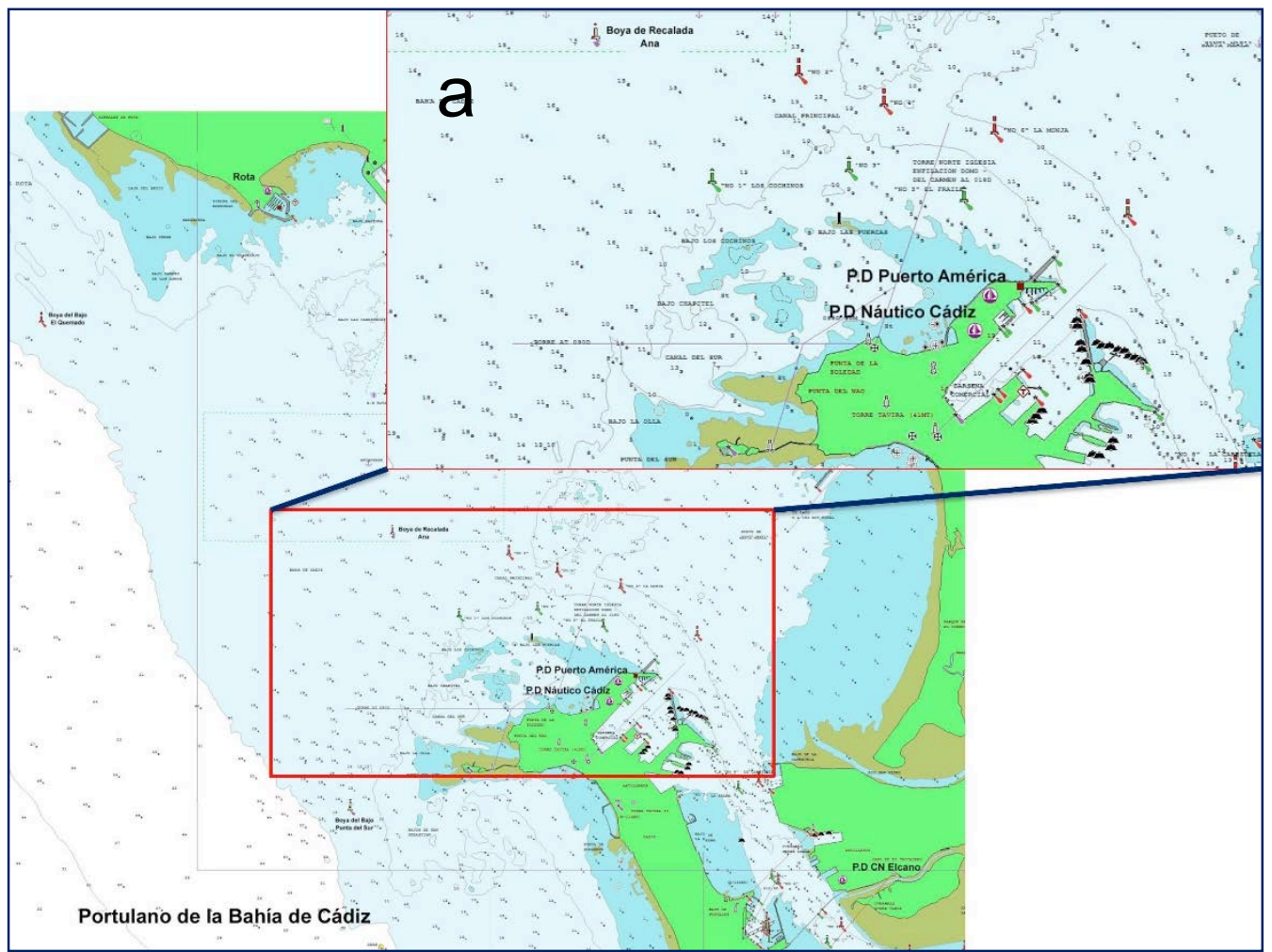

Figure 6. Chart of the Bay of Cadiz. a. Zone of practicals on board the "Tartessos".

The final practical will be made with the aid of the GPS receiver and a mobile computer connected to GE. The exercise and the application will have to be installed as standalone, without connection to the Internet, to be able to be used on board. GE was used to plan the route and the WPs and these data 
were loaded onto the GPS device. In the classroom, and with the aid of the charts of the Port of Cadiz and the List of Lights and Fog Signals [20], the course and the buoys that define the entrance channel to the port are marked in GE. Figure 6 shows the charts of the Port of Cadiz and the zone where the practicals will be carried out (Figure 6a).

This Final work, with the course in KML file format and the course planning document, must be sent using the virtual campus or by e-mail, for their assessment. The course planned in GE, and which will be followed by the "Tartessos" training vessel, is shown in Figure 7.

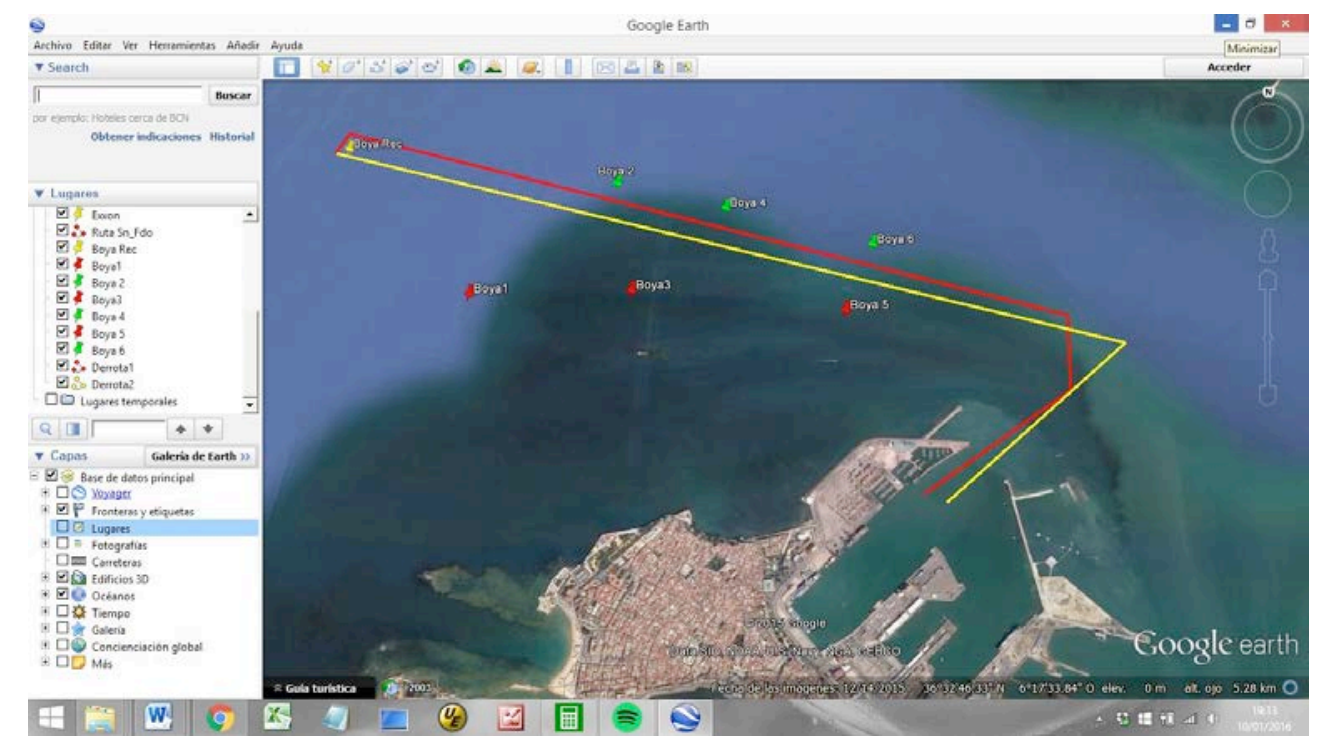

Figure 7. Course loaded and visualised in GE

\section{RESULTS AND DISCUSSION}

Although the application of this methodology is still in development, and its full implementation is pending for the present academic year, some of its results can be presented and be discussed in the future.

During the last academic year, some modifications were made in the subject, such as: improvements in the subject's virtual campus, making sufficient material available to the students to undertake online activities that improve the learning process. Field practicals have been introduced which include visits to ships of the Spanish Navy, such as the sail training ship Juan Sebastián de Elcano, and ships of the fleet in the Rota Naval Base. Also, visits will be made to technical organisations and institutions related to the Merchant Marine and navigation, such as the Naval Hydrographic Institute and the Royal Navy Institute and Observatory. The interest of the students in the subject has been boosted by these activities and by the use of the virtual campus, which can be appreciated in the campus usage statistics, given by the campus access figures and the total number of e-mails for each degree, these are shown in Figure 8.
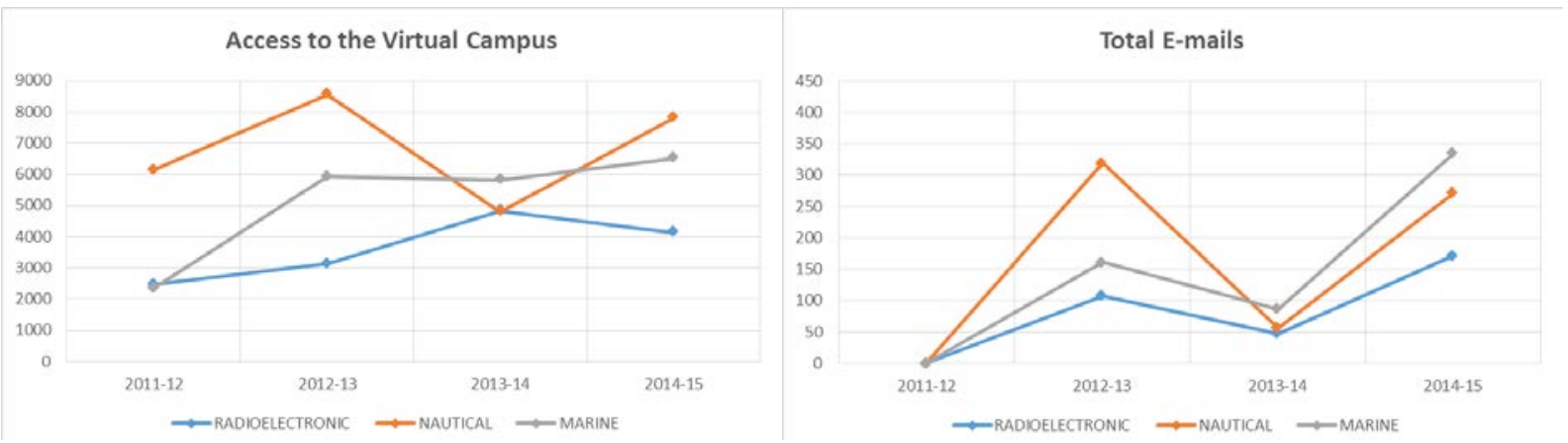

Figure 8. Access to the virtual campus and number of e-mails by degree 
In both cases, it can be seen that the trend is positive, whereby it can be anticipated that in future academic years the students will make massive use of the virtual campus, the exercises and the question bank which will help them to prepare for the final examination.

Regarding student numbers, in the 2011-12 academic year the number of places for the Degree in Nautical Engineering were filled, followed in number of students by the Degree in Marine Engineering (Engines) and the Degree in Radioelectronic Engineering. From the 2012-13 academic year there was a negative trend in graduations in the three degrees, as shown in Fig. 9.

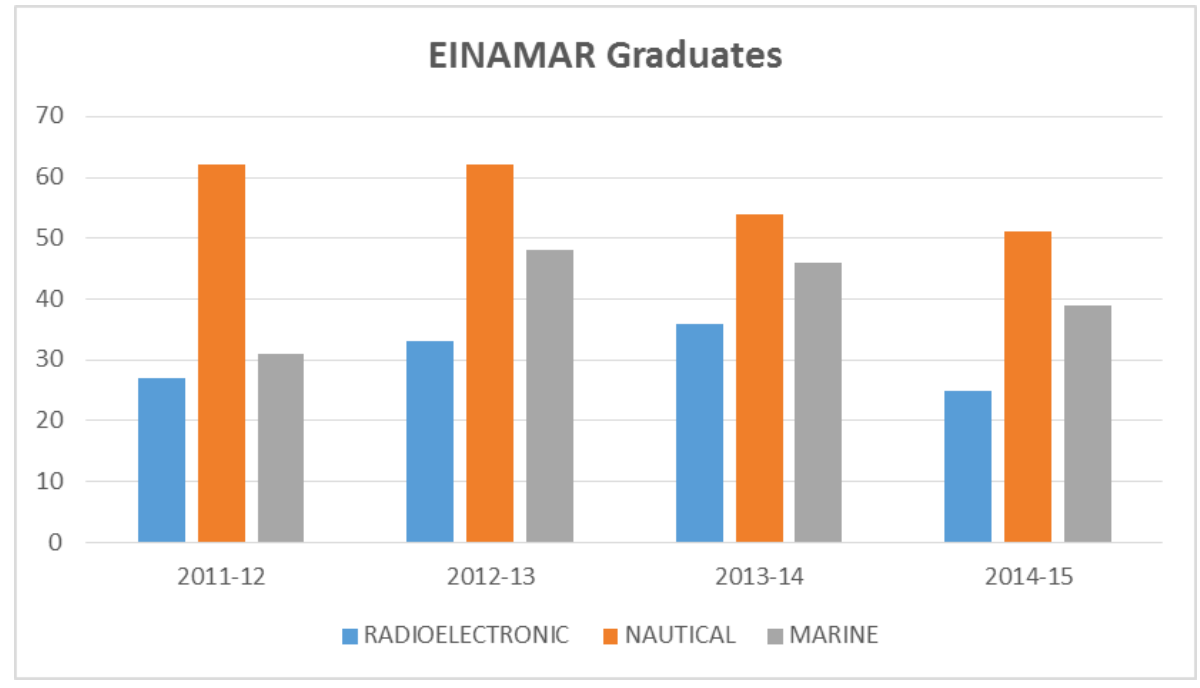

Figure 9. Graduations by academic year and degree

From the next academic year, when we will have more concrete results on the use of the virtual campus and the implementation of this methodology, we believe there could be great interest in publishing them in the repository of the University of Cadiz, and which would be of public use for the university community.

With the purpose of spreading the utility of this project in the academic sphere, conferences will be held to explain its methodology, results and conclusions, not only in EINAMAR, but also in international forums and conferences, and its application will be promoted in other Schools and Colleges where Merchant Marine degrees are taught.

\section{CONCLUSIONS}

Pending the final results of this teaching innovation project, we can conclude that these types of initiatives boost the interest of the students for the subject and the professional career that they have chosen. The virtual campus provides appropriate material for the students and contributes to improving the learning process.

The methodology presented in this document has practical utility in the knowledge of the technical part of the subject and its application in the professional field.

\section{REFERENCES}

[1] Michavila, F. (2009). Educative Innovation, Opportunities and Barriers. ARBOR Ciencia, Pensamiento y Cultura CLXXXV EXTRA 2009 3-8 ISSN: 0210-1963.

[2] Espinosa J. K., Jiménez, J., Olabe, M. A. and Basogain, X. (2006). Innovación Docente para el Desarrollo de Competencias en el EEES. Tecnologías aplicadas a la enseñanza de la Electrónica. Congreso Tecnologías Aplicadas a la Enseñanza de la Electrónica (TAEE 2006).

[3] Muñoz Perez, J. J., M Graça, N., Simona, F., Marina, M., Sebastian, S., Francisco, Coral, R. A. (2015). Methodologies for teaching an engineering subject in different countries: comparison and results. InProceedings of INTED2015 Conference 2nd-4th March 2015, Madrid, Spain. 
[4] Rubia, M. y Marbán, J.M. (2006). El Papel de las Nuevas Tecnologías en el Desarrollo de Proyectos Piloto de Innovación Docente. Revista Latinoamericana de Tecnología Educativa, 5 (2), 301-308.

[5] Navarro-Pons, M., Moreno, L., Muñoz-Perez, J. J., Anfuso, G., \& Román-Sierra, J. (2014). Success on increasing number of students that pass the coastal engineering subject. EDULEARN14 Proceedings, 4443-4448.

[6] Coll, C., Rochera, M.J., Mayordomo, R.M. and Naranjo, M. (2007). Continuous Assessment And Support For Learning: An Experience In Educational Innovation With ICT Support In Higher Education. Electronic Journal of Research in Educational Psychology, Vol 5 (3), ISSN 1696295, pp 783-804.

[7] Black, P. and Wiliam, D. (1998). Assessment and Classroom Learning, Assessment in Education, vol. 5, no. 1, pp. 7-74.

[8] Jigena B., Vidal J. and Berrocoso M. (2014). Determination of the mean sea level at Deception and Livingston islands, Antarctica. Antarctic Science 27(1), pp 101-102.

[9] Jigena-Antelo B, vidal J., Berrocoso M. (2015) Determination of the tide constituents at Livingston and Deception Islands (South Shetland Islands, Antarctica), using annual time series. DYNA 82 (191), pp. 209-218

[10] Muñoz-Pérez J.J. (2012). Ondas regulares y su aplicación a la ingeniería de costas. Servicio de Publicaciones de la Universidad de Cádiz, ISBN: 9788498284218. 102 pp.

[11] Kumm W. (1998). Radionavegación. Manual del GPS. Editorial CEAC S.A. Barcelona, España. 96 pp. ISBN 84-8019-591-6

[12] Berrocoso M., Ramírez M. E., Pérez-Peña A., Enríquez-Salamanca J. M., Fernández-Ros A., Torrecillas C. (2004). El sistema de posicionamiento global. Servicio de Publicaciones de la Universidad de Cádiz.

[13] Letham L. (2001). GPS Fácil. Editorial Paidotribo. Barcelona, España, 283 pp. ISBN 84-3291933-0

[14] Google Earth oficial web site https://www.google.com/earth/

[15] Wikipedia oficial web site https://es.wikipedia.org/wiki/Google_Earth

[16] BOE, Boletín Oficial del Estado (2014). Real Decreto 875/2014, de 10 de octubre, por el que se regulan las titulaciones náuticas para el gobierno de las embarcaciones de recreo. BOE Núm. 247 del sábado 11 de octubre de 2014, Sec. I., pag. 82978 - 83097

[17] Biggs, J. (1999). What the Student Does: Teaching for Enhanced Learning. Higher Education Research \& Development 18, Issue 1, pp. 57-75.

[18] Vilanova, R. and. Ponsa, P. (2011). Positive Effect of Increasing Feedback for Student SelfAdjustment of Learning Habits. Journal of Technology and Science Education. Vol.1 (1), 2011, pp 41.

[19] Garmin oficial web site http://www.garmin.com/es-ES

[20] IHM, instituto Hidrográfico de la Marina, (2016). Libro de Faros y Señales de Niebla. Parte I. Ministerio de Defensa de España (Eds.), I.S.S.N: 1136 - 7687. Available at: http://www.armada.mde.es/ihm/XML/LF/LF_ESPANA_COSTA\%20SW.xml 